\title{
Increased plasma total homocysteine levels increased the risk for dementia in the elderly
}

Seshadri S, Beiser A, Selhub J, et al. Plasma homocysteine as a risk factor for dementia and Alzheimer's disease. N Engl J Med 2002 Feb 14;346:476-83.

\section{QUESTION: Is an increased plasma total homocysteine concentration a risk factor for dementia in the elderly?}

Design

Cohort study with a median follow up of 8 years.

\section{Setting}

Framingham, Massachusetts, USA.

\section{Participants}

1092 elderly participants (mean age 76 y, $61 \%$ women) from the Framingham Study cohort who were free from dementia and had plasma total homocysteine levels measured at their 20th biennial examination.

\section{Assessment of risk factors}

Baseline data were collected on the plasma total homocysteine level. Analyses were adjusted for baseline age; sex; apolipoprotein E genotype (93\% of participants); plasma levels of folate ( $98 \%$ of participants), vitamin B-12 (85\% of participants), and vitamin B-6 (92\% of participants); educational status; history of stroke; cigarette smoking; alcohol intake; diabetes mellitus; systolic blood pressure; and body mass index.

\section{Main outcome measures}

Dementia (Diagnostic and Statistical Manual of Mental Disorders, 4th edition, criteria; symptoms $>6$ months in duration; and Clinical Dementia Rating scale severity of dementia score $\geq 1$ ) and Alzheimer's disease (National Institute of Neurological and Communicative Disorders and Stroke and the Alzheimer's Disease and Related Disorders Association criteria for definite, probable, or possible Alzheimer's disease). Outcome assessors were blinded to plasma total homocysteine levels.

Source of funding: National Institutes of Health.

For correspondence: Dr P A Wolf, Boston University School of Medicine, Boston, Massachusetts, USA. pawolf@bu.edu.

Abstract and commentary also appear in

Evidence-Based Mental Health

\section{Main results}

Dementia was diagnosed in 111 participants $(10 \%$ of the were diagnosed with Alzheimer's disease. After adjusting for all collected variables using a Cox proportional hazards model $(\mathrm{n}=680)$, risks for dementia (relative risk [RR] 1.4, 95\% CI 1.1 to 1.9) and Alzheimer's disease (RR 1.8 , CI 1.3 to 2.5$)$ were increased; the RRs were per increment of 1 standard deviation in the logtransformed baseline plasma total homocysteine levels. Hyperhomocysteinemia (plasma homocysteine $>14$ $\mu \mathrm{mol} / \mathrm{l}$ ) increased the risks for dementia (RR 1.9, CI 1.3 to 2.8) and Alzheimer's disease (RR 1.9, CI 1.2 to 3.0). cohort), and of those, 83 participants ( $8 \%$ of the cohort)

\section{Conclusion}

An increased plasma total homocysteine level was a risk factor for dementia in the elderly.

\section{COMMENTARY}

A risk factor may show disease causation; if it suggests a plausible intervention, then it is all the more interesting. It is even better if that intervention is preventive. Robust risk factors for Alzheimer's disease are now well established: increased age, Down's syndrome, poor education, and apolipoprotein E status. These risks are not easily altered. Biological risk factors that can be altered are especially attractive. Some, such as oestrogen use and middle-life vascular risk factor control, have accumulating evidence and suggest obvious, if awkward, interventions. The homocysteine story includes a plausible mechanism for causing Alzheimer's disease, and the suggested intervention (dietary folate supplementation) is cheap, easy, and available to all. Folate prevents neural tube defects, a finding that has already led to dietary supplementation with folate in the US.

The study by Seshadri $e t a l$ is hypothesis generating and prospectively studies 1092 participants from the Framingham Study, of whom 111 subsequently developed dementia. The wide confidence intervals of the RRs reported in the study suggest the need for caution in interpreting these results. Can they be explained because of inadequate adjustment for possible confounding factors? In addition, the findings of Seshadri et al are contrary to those from the other large prospective study of homocysteine and cognition. ${ }^{1}$ Some of these uncertainties can be resolved by doing larger studies that provide estimates of the association between homocysteine and dementia in a range of different circumstances (such as at different levels of other risk factors and at different times in the evolution of risk). Analogy with plasma risk factors in cardiovascular disease is instructive. Initial studies overestimated the role of homocysteine, and a recent synthesis of the evidence suggests that its role remains uncertain, ${ }^{2}$ even though $>10$ times the amount of information is available for cardiovascular disease than for dementia. Understanding the exact nature of the relation between homocysteine and dementia is important because the implications of this link are far reaching. Seena Fazel, BMChB, MRCPsych University of Oxford, Warneford Hospital Oxford, UK

1 Kalmijn S, Launer LJ, Lindemans J, et al. Total homocysteine and cognitive decline in a community-based sample of elderly subjects: the Rotterdam Study. Am J Epidemiol 1999; 150:283-9.

2 Danesh J, Lewington S. Plasma homocysteine and coronary heart disease: systematic review of published epidemiological studies. J Cardiovasc Risk 1998;5:229-32. 


\section{Incorporating economic analysis into clinical practice guidelines: a guide for hopeful users}

A large health plan has asked you to help them develop a clinical practice guideline for colon cancer screening. The plan currently covers annual fecal occult blood testing (FOBT) and flexible sigmoidoscopy every 5 years as screening methods. Member rates for both types of screening are very low (hence the impetus for the guideline). At the behest of several local gastroenterologists, the plan is also considering whether to cover colonoscopy every 10 years for average-risk people $\geq 50$ years of age. Part of the process involves reviewing the costeffectiveness literature, because the chief executive officer of the health plan is skeptical that colonoscopy represents a wise use of their ever-tightening budget. You are familiar with US Preventive Services Task Force Guidelines for colon cancer screening. After reviewing several recent cost-effectiveness studies, however, you find them daunting in terms of methodological complexity, terminology, and representation of outputs (a confusing array of large numerical tables and graphs that strongly resemble something you studied in first-year college economics). Is it possible to translate these studies into something you understand, believe reflects sound clinical practice, and believe would be useful to the health plan for their decision making?

The situation just described, an apparent disconnect between costs and clinical practice guidelines and the confusion it causes for readers, is not unusual. Economic analyses are rarely included in guidelines, mostly because each discipline has different and often conflicting views of what constitutes "best practice". ${ }^{2}$ This exclusion is unfortunate, because both guidelines and cost-effectiveness studies offer important information to help us practice more effective and efficient health care. Decision makers today have a need to synthesise and interpret these studies rapidly and efficiently. This editorial offers suggestions to help clinicians understand costeffectiveness studies and to use them in developing guidelines. Its approach is similar to the methods for defining and answering clinical queries used by those who practice evidence-based medicine: defining the clinical question, searching for evidence, and evaluating the quality of evidence.

\section{(1) What is the clinical problem that is the subject of the guideline?}

In this case we focus on screening options for adults $\geq 50$ years of age who do not have symptoms of and who are at average risk for colorectal cancer.

\section{(2) What interventions are being considered? What} is the default intervention, if any?

Guidelines are designed to reduce variation in care, with the goal of using treatments that have been shown to improve desirable outcomes or minimise undesirable ones. Likewise, cost-effectiveness studies most often focus on comparing new with existing care. In the case of colon cancer screening, the health plan already covers flexible sigmoidoscopy and FOBT, treatments with good evidence of efficacy. It is thus reasonable to consider the cost-effectiveness of colonoscopy compared with the following alternatives: no screening, flexible sigmoidoscopy alone, FOBT alone, and sigmoidoscopy plus FOBT.

\section{(3) Search the literature for cost-effectiveness studies}

Searching for high-quality economic articles can be laborious, and the outcomes are not always satisfactory, ${ }^{3}$ primarily because of overuse of the term cost-effectiveness in the literature. Searching for this term will retrieve many articles, but most are not formal economic analyses. To address this problem, I suggest starting by using the medical subject heading (MeSH) for cost-effectiveness analysis, that is, "cost-benefit analysis" (when searching in Medline) with other terms that are specific to the clinical situation and technologies being compared (as outlined in 1 and 2 above). For colon cancer screening in PubMed (www.ncbi.nlm.nih.gov/entrez/query.fcgi), start with "costbenefit analysis" as well as the content terms "screening, colonoscopy, sigmoidoscopy, and fecal occult blood." Although this approach is not perfect, it improves the specificity of the search and substantially reduces the volume of articles compared with using the last 4 terms alone. In this case, we retrieve 24 articles. Reviewing the abstracts, it appears that several are formal costeffectiveness analyses of all 3 screening methods. For this exercise, we select 3 recent analyses.$^{4-6}$ These will be a good start for the next phase of the evaluation.

\section{(4) What is the bottom line of each study for the interventions being considered?}

The bottom line of most economic analyses is an incremental cost-effectiveness ratio-that is, the ratio of the difference in costs over the difference in outcomes for the interventions being compared. While starting with the conclusion does not help us determine the quality of the methods, it allows us to address the question: "If this were true, could it influence how I practise (or write or implement the guidelines)?" The economic analysis could be influential, for example, if it states that a little-used treatment is highly cost-effective, or conversely, that a widely advocated treatment has poor cost-effectiveness. If your answer to the question is "no," then stop reading. If the answer is "yes," we need to go on and review the methods to answer another question: "Is it likely to be true?"

In this case, the 3 studies consider the relative values of colonoscopy, flexible sigmoidoscopy, and FOBT as screening tools for people $\geq 50$ years of age at average risk for colorectal cancer. ${ }^{4-6}$ Comparisons worth considering include the value of each compared with no screening and the incremental value of colonoscopy compared with either flexible sigmoidoscopy or FOBT. Because colonoscopy is more costly than the other approaches (at least initially) it is important to ask what one gets for this additional expenditure. Table 1 gives the results.

These results tells us 2 things. Firstly, all 3 studies conclude that compared with no screening, all strategies are reasonably cost-effective when using a (rather arbitrary, but widely cited) threshold of $\$ 50000 /$ life-year gained. Secondly, the articles 
Table 1 Cost-effectiveness of colorectal cancer screening as reported in selected articles

\begin{tabular}{|c|c|c|c|}
\hline \multirow[b]{2}{*}{ Interventions compared } & \multicolumn{3}{|c|}{$\begin{array}{l}\text { "Bottom Line" (cost per life-year } \\
\text { gained, } 1998 \text { dollars) (reference)t }\end{array}$} \\
\hline & $\begin{array}{l}\text { Sonnenberg } \\
\text { (4) }\end{array}$ & $\begin{array}{l}\text { Frazier } \\
(5)\end{array}$ & $\begin{array}{l}\text { Vijan } \\
(6)\end{array}$ \\
\hline Annual FOBT $v$ no screening & $\$ 9705$ & $\$ 12667$ & $\$ 7756$ \\
\hline $\begin{array}{l}\text { FS every } 5 \text { years } v \text { no } \\
\text { screening }\end{array}$ & $\$ 36509$ & $\$ 12571$ & $\$ 14668$ \\
\hline Colonoscopy $v$ no screening & $\$ 10983$ & $\$ 20418$ & $\$ 7019$ \\
\hline Colonoscopy $v$ annual FOBT & $\$ 11382$ & $\$ 76552$ & $\$ 6243$ \\
\hline $\begin{array}{l}\text { Colonoscopy } v \text { FS every } \\
5 \text { years }\end{array}$ & Dominatesł & $\$ 52903$ & Dominatesł \\
\hline $\begin{array}{l}\text { Colonoscopy } v \text { FS every } \\
5 \text { years plus annual FOBT }\end{array}$ & Not available & $\$ 561 \S$ & $\$ 332630 \S$ \\
\hline
\end{tabular}

${ }^{*}$ FOBT = fecal occult blood test; FS = flexible sigmoidoscopy.

†Baseline compliance: Sonnenberg $100 \%$, Frazier $60 \%$, Vijan $75 \%$.

$\ddagger$ Dominates means that the second procedure listed was more costly and less effective than the first procedure.

§FOBT plus flexible sigmoidoscopy is more expensive and more effective than colonoscopy.

reach very different conclusions regarding the incremental value of colonoscopy compared with FOBT and flexible sigmoidoscopy. Sonnenberg ${ }^{4}$ et al and $\mathrm{Vijan}^{6}$ et al state that compared with FOBT and flexible sigmoidoscopy alone, colonoscopy provides good value; study 2 finds that colonoscopy is only marginally effective.

\section{(5) What factors "drive" the outcome?}

Cost-effectiveness analyses are by nature synthetic, usually integrating data from multiple sources to derive the result. Reviewing each source (there can be dozens) for quality and accuracy is impractical for most decision makers. To help with this issue, ask: "What factors drive the outcome, that is, would have the greatest influence on the bottom line of the study if they were changed from their baseline value?" This issue, formally termed sensitivity analysis, is a logical next step for evaluating the quality of a cost-effectiveness study. As a rule of thumb, 2-4 factors usually have the greatest effect on the outcome, especially the cost and efficacy of the intervention. If the cost-effectiveness ratio changes from favourable to unfavourable (or vice versa) at plausible values for influential factors, this reduces confidence in the conclusions. $^{\mathrm{a}}$

Most cost-effectiveness studies have a sensitivity analysis section that addresses this issue. Unfortunately, it is difficult to identify the most influential factors for the 3 screening methods in the sensitivity analysis sections of the 3 studies. The 2 mentioned consistently are procedure cost and compliance. These are useful because they are seldom specifically evaluated in clinical trials and are likely to vary from setting to setting. Table 2 summarises the sensitivity analysis for these variables.
It seems that varying procedure cost or compliance across a probable range is unlikely to have an extremely adverse effect on the cost-effectiveness of the 3 strategies.

\section{(6) How valid are the most influential variables at} their default values?

If the bottom line of the study is highly dependent on specific factors, then these should be scrutinised closely. It is particularly important that influential data are based on the highest quality trials available, preferably randomised controlled trials (RCTs). Of note, the ability of colonoscopy to prevent colorectal cancer or mortality has not been measured in a randomized screening trial. Two articles base their results on 1 case-control study, ${ }^{7}$ suggesting that screening colonoscopy reduces the risk for dying of colon cancer. None of these articles would pass the screening criteria for cost-effectiveness studies used by Evidence Based Medicine which requires $\geq 1$ of the studies included in the analysis of effectiveness to be an RCT. One could easily justify ignoring these articles at this point if the purpose was simply to keep up to date. However, our purpose is to address a policy problem (about screening), and for this the lack of strong evidence should be considered in reaching a decision about colonoscopy. The effectiveness of FOBT, on the other hand, is supported by 3 large RCTs showing benefit in reducing colorectal cancerrelated mortality. ${ }^{8-10}$ Flexible sigmoidoscopy is intermediate in effectiveness, with 1 small RCT and 2 case-control studies showing benefit. ${ }^{11-13}$

\section{(7) Interpretation: how should the economic studies} influence the guidelines?

If we are reasonably confident that the economic studies are valid and cover the major clinical choices facing the organisation, next we need to consider what part (if any) they should play in shaping the guideline. These include issues that extend beyond the scope of the studies, such as implementation costs and the availability of clinicians trained in colonoscopy. Other issues, such as the first-year budget effect of adopting a particular policy, may or may not be available from the economic studies (in this case they are not). All should be considered (and weighted) in conjunction with the economic and clinical data.

The economic studies suggest that given the assumptions about efficacy, compliance, and cost, all methods-including colonoscopy-are relatively cost-effective for colorectal cancer screening compared with no screening. From an evidencebased medicine perspective, the weak supporting clinical evidence of the efficacy of colonoscopy is problematic. The clinical and economic outcomes of FOBT are more certain because efficacy rates are drawn from RCTs, and sensitivity

Table 2 Sensitivity analysis of screening v no screening for cost and compliance*

\begin{tabular}{|c|c|c|c|c|c|c|}
\hline \multirow[t]{3}{*}{ Variable } & \multicolumn{6}{|c|}{ Cost per life-year gained v no screening (1998 dollars) } \\
\hline & \multicolumn{2}{|l|}{ FOBT } & \multicolumn{2}{|c|}{ Flexible sigmoidoscopy } & \multicolumn{2}{|c|}{ Colonoscopy } \\
\hline & Best & Worst & Best & Worst & Best & Worst \\
\hline \multirow[t]{2}{*}{ Cost } & $\$ 9705 \dagger$ & $\$ 12667 \neq$ & $\$ 14668 \S$ & $\$ 36509 \dagger$ & $\$ 7019$ & $\$ 20418 \ddagger$ \\
\hline & $(\$ 4)$ & $(\$ 38)$ & $(\$ 225)$ & $(\$ 401)$ & $(\$ 550)$ & $(\$ 1012)$ \\
\hline \multirow[t]{2}{*}{ Compliance } & $\$ 5530 \S$ & $\$ 32500 \dagger$ & $\$ 5800 \ddagger$ & $\$ 22161 \S$ & $\$ 10$ 983† & $\$ 26000 \dagger$ \\
\hline & $(100 \%)$ & $(0 \%)$ & $(100 \%)$ & $(25 \%)$ & $(100 \%)$ & $(0 \%)$ \\
\hline
\end{tabular}

${ }^{*}$ Results are the most and least cost-effective outcomes among all 3 studies at the stated factor extremes (in parentheses). Direct comparability is limited because of variations in other factors and modelling techniques. Estimates at factor extremes were not available for all studies.

$\dagger=$ reference 4 .

$\ddagger=$ reference 5 .

$\S=$ reference 6 . 
analyses show that the outcomes are probably maintained across a reasonable range of costs and compliance. The same applies to a lesser extent for flexible sigmoidoscopy.

How much "worse" would colonoscopy be from a costeffectiveness standpoint if the efficacy was not as assumed? Unfortunately, this is not addressed in the economic studies. The studies together suggest that incremental gain of switching from FOBT or flexible sigmoidoscopy to colonoscopy is highly uncertain, ranging from "dominant" to very cost-ineffective. As with clinical studies, such a degree of uncertainty should make one pause before adopting a new standard of care for an organisation. Thus, the review of the cost-effectiveness and clinical evidence do not support adopting colonoscopy as a covered screening procedure at this time. At this point it is reasonable to note that "absence of proof is not proof of absence." It could well be that colonoscopy is more effective than FOBT or flexible sigmoidoscopy, even taking into account increased morbidity. However, the onus of proof rests with those who believe this is the case.

Meanwhile, the evidence and cost-effectiveness analyses support screening with FOBT (or flexible sigmoidoscopy when affordable) and justify efforts to increase utilisation of this programme. As it happens, success with such a programme would also increase the use of colonoscopy to evaluate "positive" findings by FOBT.

\section{Conclusion}

Economic analyses have much to offer in the creation of clinical practice guidelines. They often "put the pieces together" between treatment and outcome and give a sense of health value for money, this latter issue being an unavoidable fact of life in today's environment. Economic analyses should not dictate clinical practice guideline policies, but they can inform them by identifying the evidence that is available and helping to identify cost-inefficient strategies and making explicit the tradeoffs between benefit and expenditure for others.

SCOTT D RAMSEY, MD PHD Fred Hutchinson Cancer Research Center University of Washington Seattle, Washington, USA

${ }^{a}$ One-way sensitivity analyses generally understate the uncertainty in the cost-effectiveness ratio. One should can estimate confidence intervals are being used more frequently today.

1 Wallace JF, Weingarten SR, Chiou CF, et al. The limited incorporation of economic analyses in clinical practice guidelines. J Gen Intern Med 2002;17:210-20.

2 Ramsey SD. Economic analyses and clinical practice guidelines: why not a match made in heaven? J Gen Intern Med 2002;17:235-7.

3 Sassi F, Archard L, McDaid D. Searching literature databases for health care economic evaluations: how systematic can we afford to be? Med Care 2002;40:387-94.

4 Sonnenberg A, Delco F, Inadomi JM. Cost-effectiveness of colonoscopy in screening for colorectal cancer. Ann Intern Med 2000;133:573-84.

5 Frazier AL, Colditz GA, Fuchs CS, et al. Cost-effectiveness of screening for colorectal cancer in the general population. JAMA 2000;284:1954-61.

6 Vijan S, Hwang EW, Hofer TP, et al. Which colon cancer screening test? A comparison of costs, effectiveness, and compliance. Am J Med 2001;111:593-601.

7 Muller AD, Sonnenberg A. Prevention of colorectal cancer by flexible endoscopy and polypectomy. A case-control study of 32,702 veterans. Ann

8 Mandel JS, Bond JH, Church TR, et al. Reducing mortality from colorectal cancer by screening for fecal occult blood. Minnesota Colon Cancer Control Study. N Engl J Med 1993;328:1365-71

9 Hardcastle JD, Chamberlain JO, Robinson MH, et al. Randomised controlled trial of faecal-occult-blood screening for colorectal cancer. Lancet 1996;348:1472-7

10 Kronborg O, Fenger C, Olsen J, et al. Randomised study of screening for colorectal cancer with faecal-occult-blood test. Lancet 1996;348:1467-71.

11 Thiis-Evensen E, Hoff GS, Sauar J, et al. Population-based surveillance by colonoscopy: effect on the incidence of colorectal cancer. Telemark Polyp Study I. Scand J Gastroenterol 1999;34:414-20.

12 Selby JV, Friedman GD, Quesenberry CP Jr, et al. A case-control study of screening sigmoidoscopy and mortality from colorectal cancer. $N$ Engl J Med 1992;326:653-7.

13 Newcomb PA, Norfleet RG, Storer BE, et al. Screening sigmoidoscopy and colorectal cancer mortality. J Natl Cancer Inst 1992;84:1572-5.

\begin{tabular}{|c|c|c|c|}
\hline Acta Obstet Gynecol Scand & Arch Pediatr Adolesc Med & Gut & J Vasc Surg \\
\hline Age Ageing & Arch Surg & Heart & Lancet \\
\hline Am J Cardiol & Arthritis Rheum & Hypertension & Med Care \\
\hline Am J Med & $\mathrm{BJOG}$ & JAMA & Med J Aust \\
\hline Am J Obstet Gynecol & $\mathrm{BMJ}$ & J Am Coll Cardiol & N Engl J Med \\
\hline Am J Psychiatry & Br J Gen Pract & J Am Coll Surg & Neurology \\
\hline Am J Public Health & Br J Psychiatry & J Am Geriatr Soc & Obstet Gynecol \\
\hline Am J Respir Crit Care Med & Br J Surg & J Clin Epidemiol & Pain \\
\hline Ann Emerg Med & CMAJ & J Fam Pract & Pediatrics \\
\hline Ann Intern Med & Chest & J Gen Intern Med & Rheumatology \\
\hline Ann Surg & Circulation & J Infect Dis & Spine \\
\hline Arch Dis Child & Cochrane Library & J Intern Med & Stroke \\
\hline Arch Gen Psychiatry & Crit Care Med & J Neurol Neurosurg Psychiatry & Surgery \\
\hline Arch Intern Med & Diabetes Care & J Pediatr & Thorax \\
\hline Arch Neurol & Gastroenterology & & \\
\hline
\end{tabular}


How to cite material from Evidence-Based Medicine

Citation of material from the Notebook

Milne R, Hicks N. Evidence-based purchasing [EBM Note]. Evidence-Based Medicine 1996 May-Jun;1:101-2.

Citation for material taken from a structured abstract, written without attribution by a staff member

Antihypertensive drugs decrease mortality, coronary events, and stroke in elderly persons [abstract]. Evidence-Based Medicine 1996 May-Jun;4:105. Abstract of: Pearce KA, Furberg CD, Rushing J. Does antihypertensive treatment of the elderly prevent cardiovascular events or prolong life? A meta-analysis of hypertension treatment trials. Arch Fam Med 1995;4:943-50.

Citation for material taken from a commentary to an article

Olds D. Commentary on "Home visiting programmes reduce childhood injury." Evidence-Based Medicine 1996 May-Jun;4:112. Comment on: Roberts I, Kramer MS, Suissa S. Does home visiting prevent childhood injury? A systematic review of randomised controlled trials. BMJ 1996;312:29-33.

\section{Correction}

The commentary for the abstract "Increased plasma total homocysteine increased the risk of dementia in the elderly" should have acknowledged Bart Sheehan, MRCPsych (from the University Department of Psychiatry, Warneford Hospital, Oxford, UK) as first author.

1 Increased plasma total homocysteine increased the risk of dementia in the elderly [Abstract]. Evidence-Based Medicine 2002 Sep-Oct;7:160. Abstract of: Seshadri S, Beiser A, Selhub J, et al. Plasma homocysteine as a risk factor for dementia and Alzheimer's disease. N Engl J Med 2002;346:476-83.

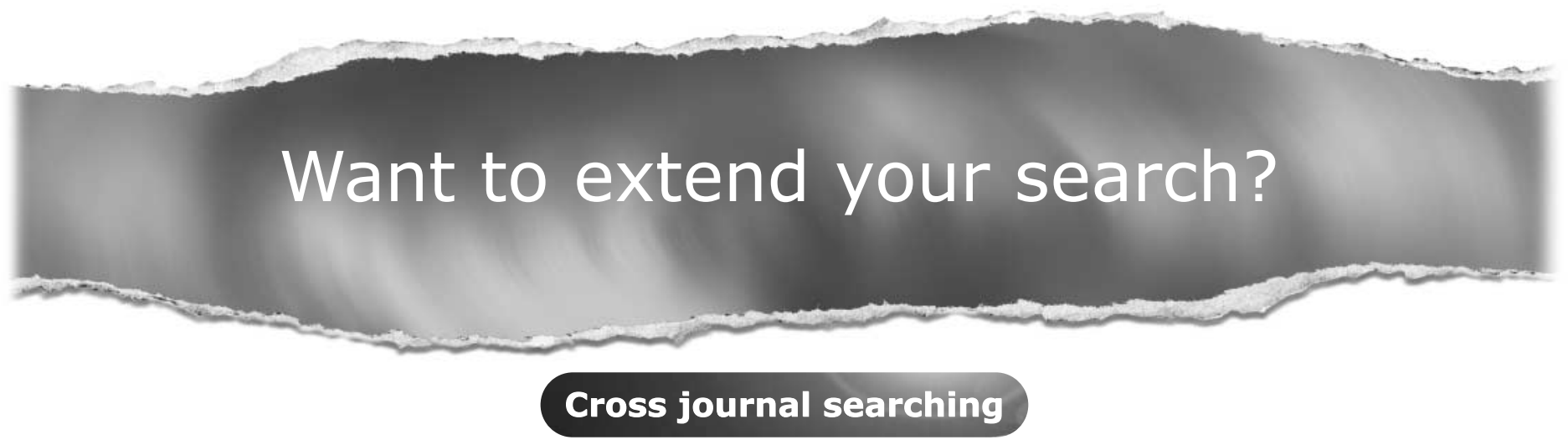

If you can't find what you are looking for in Evidence-Based Medicine you can extend your search across many of the more than 300 journals available for selection. You can restrict your search to specific subject areas (eg, clinical psychiatry, basic research), or select specific journals, or search all available titles.

\section{www.evidence-basedmedicine.com}

